\title{
ARTICLES
}

\section{EXPOSURE MODELLING IN PROPERTY REINSURANCE}

\author{
Jan Hrevuš, Luboš Marek*
}

\begin{abstract}
Exposure curves play significant role in modelling of property per risk excess of loss non-proportional reinsurance contracts, especially in the situations when not enough historical data is available for applying experience-based methods or if the underlying exposure changed significantly. The paper deals only with the first loss scale (FLS) approach which is frequently used in Europe. An alternative approach is based on ISO's PSOLD methodology which is typical for the U.S. The first research into FLS approach was done by Ruth E. Salzmann in 1963 and some further curves have been developed since that time, however, their availability is limited. According to the authors' knowledge only limited number of articles were published on this topic and no comprehensive publication which would describe the methodology to a larger extent exists. The paper provides a comprehensive description of the FLS exposure rating methodology, aims to summarise both historical and latest developments in this area and also includes various authors' own practical considerations. The theory is illustrated on numerical examples.
\end{abstract}

Keywords: reinsurance, exposure, property, non-proportional, excess of loss

JEL Classification: G22, C58, C15

\section{Introduction}

The exposure curves play very significant role in pricing of property per risk excess of loss non-proportional reinsurance treaties, especially in cases where not enough historical losses are available or the underlying exposure changed significantly. The first research on this topic was undertaken by Ruth E. Salzmann (see Salzmann, 1963), where a cumulative loss cost distribution by percentage of insured value was introduced and it was shown that for homogeneous groups of risks such distribution was stable. The research was based on the claims data of Insurance Company of North America (INA) and the fire losses incurred in 1960 as of May 31, 1961 were analysed (due to their short-tail nature it could have been assumed that the losses were already fully developed at that time). The Salzmann's curves were reviewed latter by S. Ludwig (see Ludwig, 1991) and the methodology was applied on more recent data including various practical suggestions.

* Jan Hrevuš, VIG Re zajistovna, a.s., Czech Republic (hrevus@volny.cz);

Luboš Marek, Faculty of Informatic and Statistic, University of Economics in Prague, Prague,

Czech Republic (marek@vse.cz).

This paper was written with the support of the Czech Science Foundation project No. P402/12/G097

"DYME - Dynamic Models in Economics". 
Some further exposure curves exist and are used in practice. The so called Gasser curves also known as Swiss Re curves are one of the most popular among European reinsurers. These curves are suitable for wide scope of property portfolios. On the Swiss Re curves wider related theory was demonstrated including deeper statistical description by $S$. Bernegger (Bernegger, 1997) where also $M B B E F D^{1}$ distribution class for degree of damage was introduced. The exposure curve directly expresses the percentage of the retained amount by the cedant from the total gross loss.

Although the curves are widely used, they are all based on very old data and according to authors' knowledge no recent, comprehensive and publicly available research on this topic exists. White (2005) provides a list of curves widely accepted by practitioners. The list complemented by the authors' experience is provided here:

\subsection{Lloyds curves}

The curves were historically used by London market and are based on very old data with unknown origin. The underlying data might have been marine data or even fire losses from WWII period. The curves vary neither by size of the risks nor by line of business.

\subsection{Salzmann curves}

The curves were developed in Salzmann (1963), were based on homeowners data and vary by construction (frame/brick) and by fire protection (protected/unprotected) class, i.e. four different Salzmann curves are available. The analysis was based only on building (i.e. no content etc.) fire losses from the early 1960s. Salzmann constructed the curves in order to demonstrate the methodology and meant them just as an example, she did not recommend them for further use.

\subsection{Ludwig curves}

Ludwig (Ludwig, 1991) based his curves on Hartford Insurance Group homeowners and commercial losses for accident years 1984-1988. The curves vary by construction/ protection class for homeowners and occupancy class for commercial losses, however, the commercial book analysed was very small and it is discussable if the derived curves would be also representative for large accounts. The curves also include all property covers and perils which were: wind losses, other property causes loss, and 1989 Hurricane Hugo losses.

\subsection{Swiss Re curves}

The original Swiss Re curves, also called Gasser curves, were developed by Peter Gasser based on the data of "Fire statistics of the Swiss Association of Cantonal Fire Insurance Institutions" for the years 1959-1967. The curves are widely used by European reinsurers and some recommendations for their application are available (Guggisberg, 2004). Due to their importance the curves will be described in further sections in more detailed way.

1 Maxwell-Boltzmann, Bose-Einstein and Fermi-Dirac 


\subsection{Other reinsurers' curves}

Some further curves like Munich or Skandia are used by the reinsurance market, however, their origins are not publicly documented.

\subsection{MBBEFD curves}

Bernegger (1997) built a new theoretical concept how any exposure curve can be described by two parameters function which is based on MBBEFD distribution of degree of damage. Again due to its importance the concept will be dealt in latter chapters.

\subsection{Distribution function, density function and estimates of these function.}

In our text, we often give a definition of distribution function, density function and estimates of these functions. We specify only intervals in which these functions are different from 0 or 1 . Other intervals are not interesting.

\section{Basics of Exposure Rating}

The exposure rating technique is often used in non-proportional per risk reinsurance modelling when only limited loss history of the reinsured is available or the exposure of the underlying portfolio significantly changed. This usually concerns the cases when an excess of loss reinsurance treaty for a new portfolio or treaty layers with high retentions are modelled. The exposure rating methodology is based on the so called risk profiles and the exposure curves are derived from degree of damage distributions which will be described in latter sections. It is also important to mention, that any perception of the words "rating" or "pricing" in this paper relates only to the so-called "risk reinsurance premium" which equals to estimated mean loss to reinsurance treaty layer, i.e. no profit, volatility or other loadings will be applied. Further, the paper follows the notation as stated in Daykin (1995), i.e. stochastic variables are denoted by bold letters, e.g. $\mathbf{X}$, non-stochastic variables (e.g. monetary variables) are denoted by capital letters, e.g. M. Further, ratio variables are denoted by small letters, corresponding to the capital letter of that variable from which they are derived (again, if ratio variable is stochastic, than it is denoted by small bold letter (e.g. $x$ for degree of damage).

The risk profile is a snapshot of portfolio (usually all risks come from the same line of business) where risks are allocated to bands by their value of risk (this can be e.g. maximum possible loss $\mathrm{MPL}^{2}$, sum insured or $\mathrm{EML}^{3}$ ). Each profile further includes information about

2 MPL is according to Guggisberg (2004) defined as "the maximum possible loss that occurs if all conceivable negative - and thus even improbable - circumstances accumulate in particularly unfortunate way".

3 EML is according to Guggisberg (2004) defined as "estimated maximum loss, or the largest loss that could occur under normal conditions of operation, use and loss prevention (e.g. intervention of fire brigades, operation of fixed extinguishing systems) in the building in question, whereby any exceptional circumstances (accident or unforeseen event) which could significantly alter the risk are ignored". 
the number of risks and gross premium. Let's denote the value of $i$-th risk as $V_{i}$, total gross premium for $h$-th band as $P^{h}$ and the number of risks in $h$-th band as ${ }_{r i s k} N^{h}$, then the example of risk profile typically provided for renewal purposes is shown on Table 1.

Table 1 | Example of Risk Profile for Property Portfolio

\begin{tabular}{|c|c|c|c|c|}
\hline $\boldsymbol{h}$ & \multicolumn{2}{|c|}{ Bands of $\boldsymbol{V}$} & ${ }_{\text {risk }} \boldsymbol{N}^{\boldsymbol{h}}$ & $\boldsymbol{P}^{\boldsymbol{h}}$ \\
\hline $\mathbf{1}$ & 0 & 500,000 & 528,008 & $166,891,508$ \\
\hline $\mathbf{2}$ & 500,001 & $1,000,000$ & 30,864 & $30,758,545$ \\
\hline $\mathbf{3}$ & $1,000,001$ & $1,500,000$ & 6,325 & $11,412,224$ \\
\hline $\mathbf{4}$ & $1,500,001$ & $2,000,000$ & 2,939 & $6,632,123$ \\
\hline $\mathbf{5}$ & $2,000,001$ & $2,500,000$ & 1,329 & $3,814,369$ \\
\hline $\mathbf{6}$ & $2,500,001$ & $3,000,000$ & 1,188 & $4,115,279$ \\
\hline $\mathbf{7}$ & $3,000,001$ & $3,500,000$ & 789 & $2,742,529$ \\
\hline $\mathbf{8}$ & $3,500,001$ & $4,000,000$ & 484 & $2,007,070$ \\
\hline $\mathbf{9}$ & $4,000,001$ & $4,500,000$ & 485 & $2,038,237$ \\
\hline $\mathbf{1 0}$ & $4,500,001$ & $5,000,000$ & 276 & $1,090,990$ \\
\hline $\mathbf{1 1}$ & $5,000,001$ & $6,000,000$ & 554 & $2,432,686$ \\
\hline $\mathbf{1 2}$ & $6,000,001$ & $7,000,000$ & 463 & $2,368,648$ \\
\hline
\end{tabular}

Note: All figures in EUR, fictive insurance company.

Source: Own calculations.

The idea behind the exposure rating is to estimate the expected gross loss per band and by applying the exposure curves to estimate a split of the total expected gross loss between the reinsurer and the cedant. Let's denote the total gross loss, which is random variable, arising from all risks from $h$-th band as $Z^{h}, \mathbf{Z}^{h} \in\left\langle 0 ; \sum_{i=1}^{r i s N^{h}} V_{i}^{h}\right\rangle$. The exposure curve $G(m)$ directly expresses the percentage of the retained amount by the cedant from the total gross loss and the curve can be expressed for any $i$-th risk as

$$
G(m)=r_{i, c e d}=\frac{E\left(\mathbf{Z}_{i, c e d}\right)}{E\left(\mathbf{Z}_{i}\right)},
$$

where $m$ denotes the relative retention as percentage of value of risk (normalised retention) defined as $m=\min \left(M / V_{i} ; 1\right)$. Further, $M$ denotes a retention of given excess of loss treaty layer and $E\left(\boldsymbol{Z}_{\text {i.ced }}\right)$ denotes the mean claim amount which occurred on $i$-th risk and only its portion which is retained by cedant after impact of excess of loss reinsurance. The formula (1) can be also generalised for $h$-th band as 


$$
G(m)=\frac{E\left(\mathbf{Z}_{\text {ced }}^{h}\right)}{E\left(\mathbf{Z}^{h}\right)},
$$

where $E\left(\boldsymbol{Z}_{\text {ced }}^{h}\right)$ denotes mean retained claim amount by the cedant from all losses originating from all risks allocated to $h$-th risk profile band (assuming unlimited reinsurance layer capacity). Some of the curves commonly used by European reinsurers are demonstrated on Figure 1.

\subsection{Exposure curves and which curve to choose}

The theoretical background for construction of the curves will be described further, however, at this stage some thoughts how to select the appropriate curve will be discussed. The exposure curve is derived from distribution of degree of damage which is random variable and will be further denoted as $\mathbf{x}, \mathbf{x} \in\langle 0 ; 1\rangle$ and defined as

$$
\mathbf{x}=\frac{\mathbf{X}}{V},
$$

where $\mathbf{X}$ denotes a random variable describing gross amount (i.e. before application of reinsurance) of individual claim and $V$ denotes value of the respective risk on which the given claim occurs.

Figure 1 | Total, Swiss Re and Lloyd's Exposure Curves

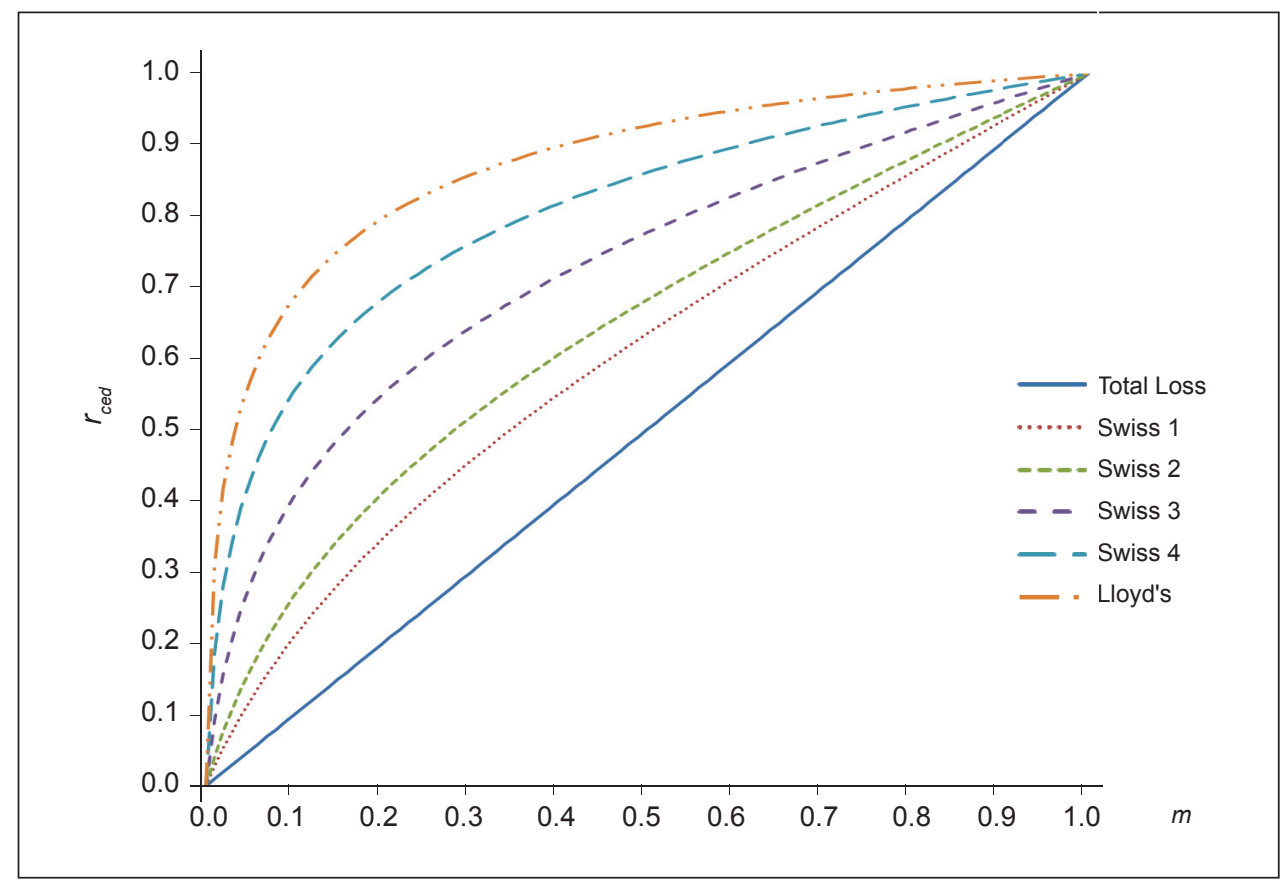

Source: Guggisberg (2004), Bernegger (1997), own calculations 
It will be shown in further sections that the curves tending more towards to the diagonal are suitable for portfolios characterised by total or higher degree of damage. Typical example can be fire insurance for residential property risks where the fire usually causes substantial loss related to the value of respective risk. For such type of risks Swiss 1 curve would be suitable.

On the other hand, the more the curve runs to the outer area, the less probable the total loss is and such portfolios are characterised rather by partial losses (lower average degree of damage). Typical example for such risk would be fire industrial insurance. The industrial complexes are usually well equipped by various types of fire protection measures and it can be well expected that the fire loss would be relatively low compared to the value of given risk. According to Guggisberg (2004) following aspects when selecting the curve must be considered.

\section{Perils covered in the portfolio}

Fire typically causes more damage to an individual building than windstorm which in many cases damages just the roofs. Gas explosion can completely destroy the whole building, losses caused by floods and earthquakes are dependent on their strengths.

\section{Class of risk}

The gunpowder factories are more exposed to total loss than for example airport buildings with good fire protection.

\section{Size of risk}

Fire often causes only partial damage to large buildings or industrial plants, whereas small risks are more exposed to suffer total loss. The good indicator how to measure the size (value) of the risks is by sums insured or MPL.

All the aspects above must be considered simultaneously and useful rough guide for choice of the exposure curve is provided in Table 2.

Table 2 | Choice of Exposure Curve by Peril and Class of Risk From

\begin{tabular}{|l|l|l|l|}
\hline & \multicolumn{1}{|c|}{$\begin{array}{c}\text { Curve tends } \\
\text { towards the diagonal }\end{array}$} & \multicolumn{1}{|c|}{$\begin{array}{c}\text { Curve runs } \\
\text { in the middle area }\end{array}$} & \multicolumn{1}{c|}{$\begin{array}{c}\text { Curve runs } \\
\text { in the outer area }\end{array}$} \\
\hline \multirow{2}{*}{ Fire } & \multicolumn{1}{|c|}{ EML } & \multicolumn{1}{c|}{ MPL } & \multicolumn{1}{c|}{ SI } \\
\hline & $\begin{array}{l}\text { Risks with poor fire } \\
\text { protection }\end{array}$ & $\begin{array}{l}\text { Risks with average fire } \\
\text { protection }\end{array}$ & $\begin{array}{l}\text { Risks with good, above- } \\
\text { average fire protection }\end{array}$ \\
\cline { 2 - 5 } & Personal lines & Commercial lines & Industrial lines \\
\cline { 2 - 5 } & Farm building & Industrial building & Administrative building \\
\hline \multirow{2}{*}{ Windstorm } & - & Radio tower & Office building \\
\hline Hurricane & Radio tower & Office building & \multicolumn{1}{|c}{} \\
\hline
\end{tabular}

Source: Guggisberg (2004) 


\subsection{Steps in FLS exposure rating process}

After receiving the risk profile (e.g. as shown in Table 1) the procedure of exposure rating can be conducted in the following steps:

1. Setting mean $\bar{V}^{h}$ for each band either as mid of the $h$-th band or if aggregated value of risk per band or per individual risks is provided then

$$
\bar{V}^{h}=\frac{\sum_{i=1}^{r i s k} N_{i}^{h} V_{i}^{h}}{r i s k} N^{h} .
$$

2. $\quad$ Setting mean normalised retention $\bar{m}^{h}$ for each band $h$ as

$$
\bar{m}^{h}=\min \left(\frac{M}{\bar{V}^{h}} ; 1\right) .
$$

3. Choice of appropriate exposure curve for each band.

4. For each band calculating value of exposure curve function $G\left(\bar{m}^{h}\right)$.

5. Estimating mean gross loss per band.f

As only gross premiums per band are usually provided, then the estimated mean total gross loss per band shall be calculated as

$$
\hat{E}\left(\mathbf{Z}^{h}\right)=P^{h} \hat{\mathbf{q}}^{h},
$$

where $\hat{\mathbf{q}}^{h}$ denotes estimated gross loss ratio for $h$-th band. This information can be obtained directly from the client or based on market experience.

6. Estimating ceded loss (reinsurer's share) per band from

$$
\hat{E}\left(\mathbf{Z}_{r e}{ }^{h}\right)=\left(1-G\left(\bar{m}^{h}\right)\right) \hat{E}\left(\mathbf{Z}^{h}\right) .
$$

7. Considering only one layer with retention $M$ and unlimited capacity, then the estimated mean total ceded loss into the layer can be expressed as

$$
\hat{E}\left(\mathbf{Z}_{r e}\right)=\sum_{h=1}^{H} \hat{E}\left(\mathbf{Z}_{r e}^{h}\right) .
$$

for all bands $\mathrm{h}=\{1,2, \ldots, H\}$.

Assuming enough reinsurance capacity is obtained by the cedant, i.e. the highest value of any risk is within the treaty capacity, then in case of more layers with corresponding retentions denoted as ${ }^{(s)} M, s=\{1,2, \ldots, S\}$ the formula (9) can be expressed for the $h$-th band and $s$-th layer as

$$
\hat{E}\left({ }^{(s)} \mathbf{Z}_{r e}{ }^{h}\right)=\begin{array}{ll}
\left(G\left({ }^{(s+1)} \bar{m}^{h}\right)-G\left({ }^{(s)} \bar{m}^{h}\right)\right) \hat{E}\left(\mathbf{Z}^{h}\right) & \text { for } s<S \\
\left(1-G\left({ }^{(s)} \bar{m}^{h}\right)\right) \hat{E}\left(\mathbf{Z}^{h}\right) & \text { for } s=S .
\end{array}
$$

Further, the mean aggregated loss ceded to the $s$-th layer can be expressed as

$$
\hat{E}\left({ }^{(s)} \mathbf{Z}_{r e}\right)=\sum_{h=1}^{H} \hat{E}\left({ }^{(s)} \mathbf{Z}_{r e}^{h}\right) .
$$




\subsection{Numerical example}

The example in Table 3 follows the risk profile from Table 1 for retention of $M=1$ Mio. EUR, and treaty limit of $L=6$ Mio. EUR. Unlimited number of free reinstatements is further considered for simplification, the estimated loss ratio $\hat{\mathbf{q}}^{h}$ is flat for all $h$ and amounts to $\hat{\mathbf{q}}^{h}=45 \%$, the selected exposure curve is Swiss $4^{4}$. Following all the steps above, the gross premium for all risks is $P=236$ Mio. EUR and corresponding estimated gross loss $\hat{E}(\mathbf{Z})=106$ Mio. EUR. The estimated mean ceded loss (i.e. risk reinsurance premium) for selected parameters would be $\hat{E}\left(\mathbf{Z}_{r e}\right)=2.9$ Mio. EUR which leads to the risk reinsurance rate of $1.23 \%$ (results generously rounded, for more precise results please see Table 3 ).

Table 3 | Exposure Rating Example

\begin{tabular}{|l|r|r|r|r|r|r|r|r|}
\hline $\boldsymbol{h}$ & \multicolumn{2}{|c|}{ Bands of $\boldsymbol{V}$} & \multicolumn{1}{c|}{${ }_{\text {risk }} \boldsymbol{N}^{\boldsymbol{h}}$} & \multicolumn{1}{c|}{$\boldsymbol{P}^{\boldsymbol{h}}$} & \multicolumn{1}{c|}{$\hat{\boldsymbol{E}}(\mathbf{Z})$} & $\overline{\boldsymbol{m}}^{\boldsymbol{h}}$ & $\boldsymbol{G}^{\prime}\left(\overline{\boldsymbol{m}}^{\boldsymbol{h}}\right)$ & $\hat{\mathbf{E}}\left(\mathbf{Z}_{\boldsymbol{r e}}^{\boldsymbol{h}}\right)$ \\
\hline $\mathbf{1}$ & 0 & 500,000 & 528,008 & $166,891,508$ & $75,101,179$ & 1.00 & 1.00 & 0 \\
\hline $\mathbf{2}$ & 500,001 & $1,000,000$ & 30,864 & $30,758,545$ & $13,841,345$ & 1.00 & 1.00 & 0 \\
\hline $\mathbf{3}$ & $1,000,001$ & $1,500,000$ & 6,325 & $11,412,224$ & $5,135,501$ & 0.80 & 0.95 & 231,553 \\
\hline $\mathbf{4}$ & $1,500,001$ & $2,000,000$ & 2,939 & $6,632,123$ & $2,984,455$ & 0.57 & 0.89 & 336,341 \\
\hline $\mathbf{5}$ & $2,000,001$ & $2,500,000$ & 1,329 & $3,814,369$ & $1,716,466$ & 0.44 & 0.84 & 281,016 \\
\hline $\mathbf{6}$ & $2,500,001$ & $3,000,000$ & 1,188 & $4,115,279$ & $1,851,875$ & 0.36 & 0.80 & 375,824 \\
\hline $\mathbf{7}$ & $3,000,001$ & $3,500,000$ & 789 & $2,742,529$ & $1,234,138$ & 0.31 & 0.77 & 286,311 \\
\hline $\mathbf{8}$ & $3,500,001$ & $4,000,000$ & 484 & $2,007,070$ & 903,181 & 0.27 & 0.74 & 233,651 \\
\hline $\mathbf{9}$ & $4,000,001$ & $4,500,000$ & 485 & $2,038,237$ & 917,207 & 0.24 & 0.72 & 258,066 \\
\hline $\mathbf{1 0}$ & $4,500,001$ & $5,000,000$ & 276 & $1,090,990$ & 490,946 & 0.21 & 0.69 & 150,688 \\
\hline $\mathbf{1 1}$ & $5,000,001$ & $6,000,000$ & 554 & $2,432,686$ & $1,094,709$ & 0.18 & 0.66 & 368,139 \\
\hline $\mathbf{1 2}$ & $6,000,001$ & $7,000,000$ & 463 & $2,368,648$ & $1,065,892$ & 0.15 & 0.63 & 395,192 \\
\hline Sum & - & - & 573,704 & $236,304,208$ & $106,336,894$ & - & - & $2,916,780$ \\
\hline
\end{tabular}

Source: Own calculations

The advantage of the basic exposure rating approach as described above is that it can be relatively easily applied. However, the whole procedure allows significant degree of subjectivity when choosing appropriate exposure curve and loss ratio. Further, basic application of this method does not provide any characteristics of volatility or the loss distribution, these problems are solved in the following sections.

$4 \quad$ Assumption for using one exposure curve made just for illustrative purposes. The curve is suitable for portfolios with higher values of risk (commercial or industrial portfolios) and in practice it would be used only for higher bands. 


\subsection{Theoretical background}

This section is further inly based on Bernegger (1997) where two-parameter family of analytical functions for modelling exposure curves and loss distributions was introduced. Despite the year of publishing (1997), it is probably still the most developed theoretical concept describing exposure curves background and also the concept gives more freedom to underwriters and pricing actuaries to define their own desired exposure curves as until that time only few discrete curves were available in practice.

Besides to already in previous sections introduced random variable degree of damage $\mathbf{x}$ and deterministic ratio of normalized retention denoted as $m$, the distribution function $F(x)$ is defined on interval $\langle 0,1\rangle^{5}$ and according to Bernegger (1997) its limited expected value function is defined as

$$
L(m)=E[\min (m, \mathbf{x})] .
$$

Further, the expected retained loss by the cedant is defined as $E\left(\mathbf{X}_{c e d}\right)=V \cdot L(m)$ and the expected ceded loss as $E\left(\mathbf{X}_{r e}\right)=V \cdot(L(1)-L(m))$. The ratio of losses retained by cedant is given by the relative limited expected value function $G(m)=L(m) / L(1)$ which is also known as exposure curve function and is expressed as

$$
G(m)=\frac{L(m)}{L(1)}=\frac{\int_{0}^{m}(1-F(x)) d x}{\int_{0}^{1}(1-F(x)) d x}=\frac{\int_{0}^{m}(1-F(x)) d x}{E(x)} .
$$

According to Bernegger (1997), the distribution function of normalized loss $F(x)$ can be derived from

$$
G^{\prime}(m)=\frac{1-F(m)}{E(\mathbf{x})}
$$

and with $F(0)=0$ and $G^{\prime}(0)=1 / E(\mathbf{x})$ is the distribution function of degree of damage has the form

$$
F(x)=\left\{\begin{array}{cl}
1 & x=1 \\
1-\frac{G^{\prime}(x)}{G^{\prime}(0)} & 0 \leq x<1 .
\end{array}\right.
$$

The expected degree of damage has the form

$$
E(\mathbf{x})=\frac{1}{G^{\prime}(0)}
$$

and the probability of total loss is further defined as

$$
p=P(\mathbf{x}=1)=\frac{G^{\prime}(1)}{G^{\prime}(0)}=G^{\prime}(1) \cdot E(\mathbf{x}) .
$$

The properties of exposure curves are that they are concave and increasing functions on the interval $\langle 0 ; 1\rangle$ with $G(0)=0$ and $G(1)=1$ and also $0 \leq P(\mathbf{x}=1) \leq E(\mathbf{x}) \leq 1$.

$5 \quad$ Any underinsurance is not assumed, i.e. incurred loss amount cannot be higher than the corresponding value of risk. 


\subsection{Example of basic approach to constructing piecewise linear exposure curve}

In order to demonstrate how exposure curve can be determined 20 claims were simulated from lognormal distribution, where $\mathbf{X} \sim L N(10.6 ; 3.6)$ whose parameters correspond to mean gross claim of $E(\mathbf{X})=250,000$ and standard deviation of gross claim $\sqrt{\operatorname{Var}(\mathbf{X})}=1,500,000$ (all further monetary amounts are in EUR if not stated differently). The corresponding degree of damage values were simulated independently from MBBEFD distribution with Swiss $3^{6}$ curve parameters, the simulated values are shown in Table 4 and the empirical distribution function of $x$ on Figure 2. Further, from formula (13) and Table 4 the following ratio is received

$$
G(m)=\frac{\int_{0}^{m}(1-F(x)) d x}{\hat{E}(\mathbf{x})}=\frac{\int_{0}^{m}(1-F(x)) d x}{0.0979}, m>0 .
$$

\section{Table 4 | Exposure Rating Example}

\begin{tabular}{|c|c|c|c|}
\hline$i$ & $x_{i}$ & $x_{i}$ & $v_{i}$ \\
\hline 1 & 70,184 & 0.012 & $5,622,140$ \\
\hline 2 & 365,443 & 0.062 & $5,872,593$ \\
\hline 3 & 106,710 & 0.005 & $21,912,266$ \\
\hline 4 & 5,697 & 0.015 & 387,735 \\
\hline 5 & $2,343,391$ & 0.029 & $82,108,438$ \\
\hline 6 & 18,091 & 0.144 & 125,468 \\
\hline 7 & 139,658 & 0.102 & $1,365,561$ \\
\hline 8 & 33,822 & 0.062 & 545,521 \\
\hline 9 & 5,838 & 0.309 & 18,904 \\
\hline 10 & 39,327 & 0.023 & $1,679,923$ \\
\hline 11 & 348,997 & 0.072 & $4,816,840$ \\
\hline 12 & 13,347 & 0.005 & $2,432,933$ \\
\hline 13 & 244,148 & 0.042 & $5,801,111$ \\
\hline 14 & 6,012 & 0.014 & 421,864 \\
\hline 15 & 53,340 & 0.005 & $10,938,014$ \\
\hline 16 & 9,807 & 0.023 & 432,773 \\
\hline 17 & 44,890 & 0.005 & $9,603,076$ \\
\hline 18 & 13,030 & 0.020 & 651,364 \\
\hline 19 & 324 & 0.007 & 45,265 \\
\hline 20 & 63,227 & 1.000 & 63,227 \\
\hline$\hat{E}(X)$ & 196,264 & 0.098 & $7,742,251$ \\
\hline$\sqrt{\hat{\operatorname{Var}(x)}}$ & 504,197 & 0.218 & $17,846,246$ \\
\hline
\end{tabular}

Source: Own calculations

$6 \quad$ All parameters for probabilistic distributions of loss severity and degree of loss selected for illustrative purposed, use of MBBEFD distribution will be discussed latter. 
The amount of $9.79 \%$ in denominator of formula (18) is the estimated mean degree of damage and is represented by the area above the CDF curve on Figure 2, whilst e.g. for $m=7 \%$ the numerator is represented by the area above the curve and bounded by the dotted curve on its right side. For the relative retention of $m=7 \%$ the value of respective exposure curve is

$$
G(0.07)=\frac{\int_{0}^{0.07}(1-F(x)) d x}{0.0979}=\frac{0.034}{0.0979}=0.347 .
$$

Figure 2 | Empirical Distribution Function $F(x)$

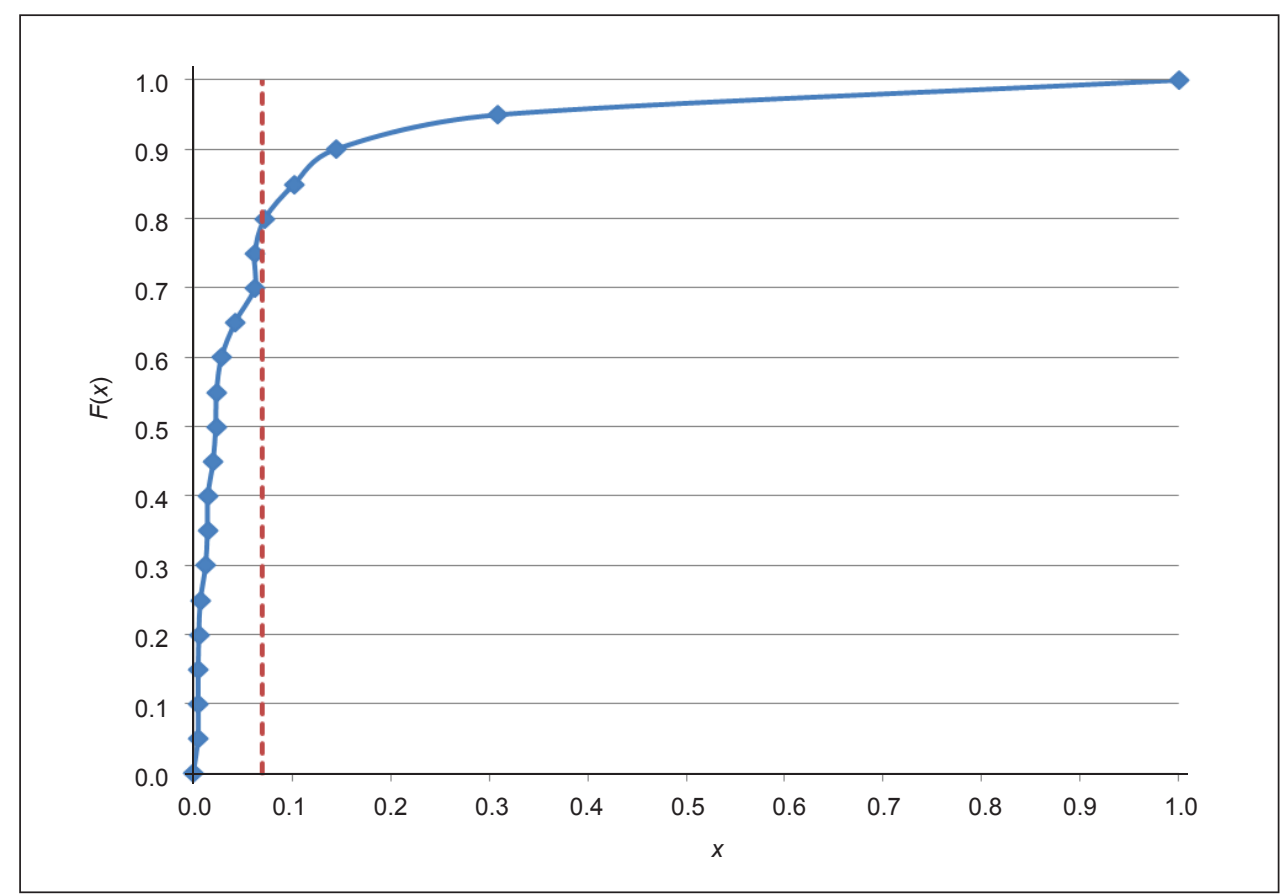

Source: Own calculations

Remark 1: This EDF is not continuous, of course. It is step function in general. But it is very difficult to show the steps in software. Therefore, this Figure 2 is a simplified view only.

As $m \in\langle 0 ; 1\rangle$, the values of corresponding piecewise linear exposure curve for all $m$ are determined in Table 5 and also shown graphically on Figure 3. 
Table 5 | Calculated Values of Exposure Curve

\begin{tabular}{|c|c|}
\hline$m$ & $\mathbf{G}(m)$ \\
\hline$<0.0000 ; 0.0047)$ & $(1 / 0.0979)(0+m)$ \\
\hline$<0.0047 ; 0.0048)$ & $(1 / 0.0979)(0.0002+0.95 m)$ \\
\hline$<0.0048 ; 0.0049)$ & $(1 / 0.0979)(0.0005+0.90 m)$ \\
\hline$<0.0049 ; 0.0055)$ & $(1 / 0.0979)(0.0007+0.85 m)$ \\
\hline$<0.0048 ; 0.0072)$ & $(1 / 0.0979)(0.0010+0.80 m)$ \\
\hline$<0.0048 ; 0.0125)$ & $(1 / 0.0979)(0.0014+0.75 m)$ \\
\hline$<0.0048 ; 0.0142)$ & $(1 / 0.0979)(0.0020+0.70 m)$ \\
\hline$<0.0048 ; 0.0147)$ & $(1 / 0.0979)(0.0027+0.65 m)$ \\
\hline$<0.0048 ; 0.0200)$ & $(1 / 0.0979)(0.0034+0.60 m)$ \\
\hline$<0.0048 ; 0.0227)$ & $(1 / 0.0979)(0.0044+0.55 m)$ \\
\hline$<0.0048 ; 0.0234)$ & $(1 / 0.0979)(0.0056+0.50 m)$ \\
\hline$<0.0048 ; 0.0285)$ & $(1 / 0.0979)(0.0067+0.45 m)$ \\
\hline$<0.0048 ; 0.0421)$ & $(1 / 0.0979)(0.0082+0.40 m)$ \\
\hline$<0.0048 ; 0.0620)$ & $(1 / 0.0979)(0.0103+0.35 m)$ \\
\hline$<0.0048 ; 0.0622)$ & $(1 / 0.0979)(0.0134+0.30 m)$ \\
\hline$<0.0048 ; 0.0725)$ & $(1 / 0.0979)(0.0165+0.25 m)$ \\
\hline$<0.0048 ; 0.1023)$ & $(1 / 0.0979)(0.0201+0.20 m)$ \\
\hline$<0.0048 ; 0.1442)$ & $(1 / 0.0979)(0.0252+0.15 m)$ \\
\hline$<0.0048 ; 0.3088)$ & $(1 / 0.0979)(0.0324+0.10 m)$ \\
\hline$<0.0048 ; 1.0000)$ & $(1 / 0.0979)(0.0479+0.05 m)$ \\
\hline
\end{tabular}

Source: Own calculations, based on values in Table 4.

\section{Figure 3 | Empirical Distribution Function $\mathbf{G}(m)$}

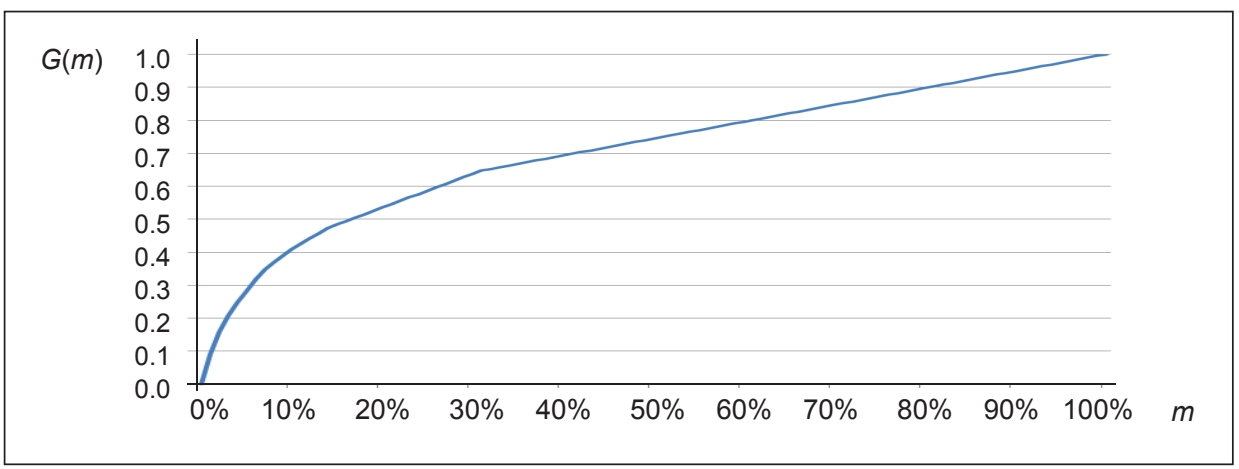

Source: Own calculations

Because we work with EDF, the Remark 1 is valid for this EDF, too. 


\section{MBBEFD Distribution Approach}

Although the previously discussed approach is continuous, practical implementation without further theoretical extension allows only construction of piecewise linear function which when based only on limited number of observations is not always suitable for further calculations. Bernegger (1997) came with an idea of implementing MBBEFD distribution class also into insurance risk theory and proved it to be very appropriate for modelling probability distribution of degree of damage on the interval $\mathbf{x} \in\langle 0 ; 1\rangle$. His approach is widely used by European reinsurance actuaries.

In his paper Bernegger described parameters $b \in\langle 0, \infty), g \in\langle 1, \infty)$ and normalised retention $m \in\langle 0 ; 1\rangle$ two parameters exposure curve in a form of

$$
G_{b, g}(m)= \begin{cases}\frac{\ln (1+(g-1) m)}{\ln (g)} & g=1 \vee b=0 \\ \frac{1-b^{m}}{1-b} & b=1 \wedge g>1 \\ \frac{\ln \left(\frac{(g-1) b+(1-g b) b^{m}}{1-b}\right)}{\ln (g b)} & b>0 \wedge b \neq 1 \wedge b g \neq 1 \wedge g>1 .\end{cases}
$$

Based on MBBEFD distributed degree of damage $x$ and corresponding distribution function for degree of damage of

$$
F(x)= \begin{cases}1 & x=1 \\ 0 & x<1 \wedge(g=1 \vee b=0) \\ 1-\frac{1}{1+(g-1) x} & x<1 \wedge b=1 \wedge g>1 \\ 1-b^{x} & x<1 \wedge b g=1 \wedge g>1 \\ 1-\frac{1-b}{(g-1) b^{1-x}+(1-g b)} & x<1 \wedge b>0 \wedge b \neq 1 \wedge b g \neq 1 \wedge g>1 .\end{cases}
$$

Further, density function of degree of damage is defined as 


$$
f(x)= \begin{cases}0 & g=1 \vee b=0 \\ \frac{g-1}{(1+(g-1) x)^{2}} & b=1 \wedge g>1 \\ -\ln (b) b^{x} & b g=1 \wedge g>1 \\ \frac{(b-1)(g-1) \ln (b) b^{1-x}}{\left((g-1) b^{1-x}+(1-g b)\right)^{2}} & b>0 \wedge b \neq 1 \wedge b g \neq 1 \wedge g>1\end{cases}
$$

and mean degree of damage is from Bernegger (1997) defined as

$$
E(\mathbf{x})=\frac{1}{G^{\prime}(0)}= \begin{cases}1 & g=1 \vee b=0 \\ \frac{\ln (g)}{g-1} & b=1 \wedge g>1 \\ \frac{b-1}{\ln (b)}=\frac{g-1}{\ln (g) g} & b g=1 \wedge g>1 \\ \frac{\ln (g b)(1-b)}{\ln (b)(1-g b)} & b>0 \wedge b \neq 1 \wedge b g \neq 1 \wedge g>1\end{cases}
$$

and the total loss probability as

$$
p=\mathrm{P}(\mathbf{x}=1)=\frac{G^{\prime}(1)}{G^{\prime}(0)}=\frac{1}{g} .
$$

\subsection{Exposure curve fitting}

We know type of distribution, but we do not know the exact parameters values. It is necessary to estimate parameters. Several ways how to estimate the $b$ and $g$ parameters exist. Bernegger (1997) recommends methods of moments (MM), whilst use of maximum likelihood method (ML) or least squares method on either empirical exposure curve or distribution function of degree of damage $F(x)$ might be also possible and will be further tested.

\section{Exposure curve fitting based on estimations of $\hat{E}(x)$ and $\hat{P}(M M)$}

Bernegger (1997) showed that for each given pair of functional $p=1 / q$ and $E$ (x) fulfilling condition $0 \leq p \leq E(\mathbf{x}) \leq 1$ only one distribution function belonging to the MBBEFD class exists. The parameter $p$ can be computed directly from the formula (23) and the other parameter $b$ by solving the equations from (22) or iteratively for general case 


$$
E(\mathbf{x})=\frac{\ln (g b)(1-b)}{\ln (b)(1-g b)} .
$$

This method will be further denoted as $\mathrm{MM}^{7}$.

\section{Exposure curve fitting based on maximum likelihood method (ML)}

As the distribution of $\mathrm{x}$ is known, the maximum likelihood method for estimating the unknown parameters $b, g$ is also a suitable option. The likelihood function which needs to be maximised has (from formula (21)) for the general case the following form:

$$
l(b, g)=\prod_{i=1}^{N} f\left(x_{i} \mid \mathrm{b}, \mathrm{g}\right)=\prod_{i=1}^{N} \frac{(b-1)(g-1) \ln (b) b^{1-x_{i}}}{\left((g-1) b^{1-x_{i}}+(1-g b)\right)^{2}}
$$

and its logarithm

$$
\ln l(b, g)=\sum_{i=1}^{N} \ln \frac{(b-1)(g-1) \ln (b) b^{1-x_{i}}}{\left((g-1) b^{1-x_{i}}+(1-g b)\right)^{2}} .
$$

The further step in this method would be finding maximum of $\ln /\left(x_{i} \mid b, g\right)$ by solving the set of equations:

$$
\begin{aligned}
& \frac{\partial \ln l(b, g)}{\partial b}=0 \\
& \frac{\partial \ln l(b, g)}{\partial g}=0 .
\end{aligned}
$$

Unfortunately, the set of equations (27) cannot be solved analytically and unknown parameters have to be calculated iteratively from formulas (25) or (26).

\section{Exposure curve based on fitting the distribution function $F(x)$ by non-linear regression}

Once the empirical distribution of degree of damage is obtained, $t$ is possible to fit theoretical distribution to empirical distribution one as described in the formula (21) and estimate parameters $b, g$. The exposure curve is further derived by applying the estimated parameters to formula (20). Advantage of this method is that the MBBEFD distribution parameters are directly obtained.

\section{Direct exposure curve fitting (DF MBBEFD)}

Further alternative how to estimate the unknown parameters of MBBEFD is direct fit of the function (20) based on the empirical exposure curves. Such approach gives very good results and also allows for further stochastic modelling as the probabilistic distribution can be fully parameterised.

$7 \quad$ MM from method of moments, however, use of such name is not exact in this case as $p$ is not any moment. 


\section{Direct exposure curve fitting by polynomial function (DF PL)}

This is a task from non-linear regression and two parameters exposure curve in the following form can be fitted:

$$
G_{\beta_{1}, \beta_{2}}(m)=\beta_{1}\left(m-m^{2}\right)+m^{\beta_{2}} \quad \text { for } \quad 0 \leq m \leq 1 ; 0 \leq G(m) \leq 1
$$

Such curve gives a very good fit of the empirical exposure curve. Various approaches as described above were compared on the example from the Figure 3 and are visualised on the Figure 4. For parameterisation of all the curves below the solver included in MS Excel 2007 was used, namely the Newton iterative method to minimise the squared residuals or to maximise the logarithm of likelihood function ${ }^{8}$.

Figure 4 | Comparison of Various Approaches to Fitting the Exposure Curves

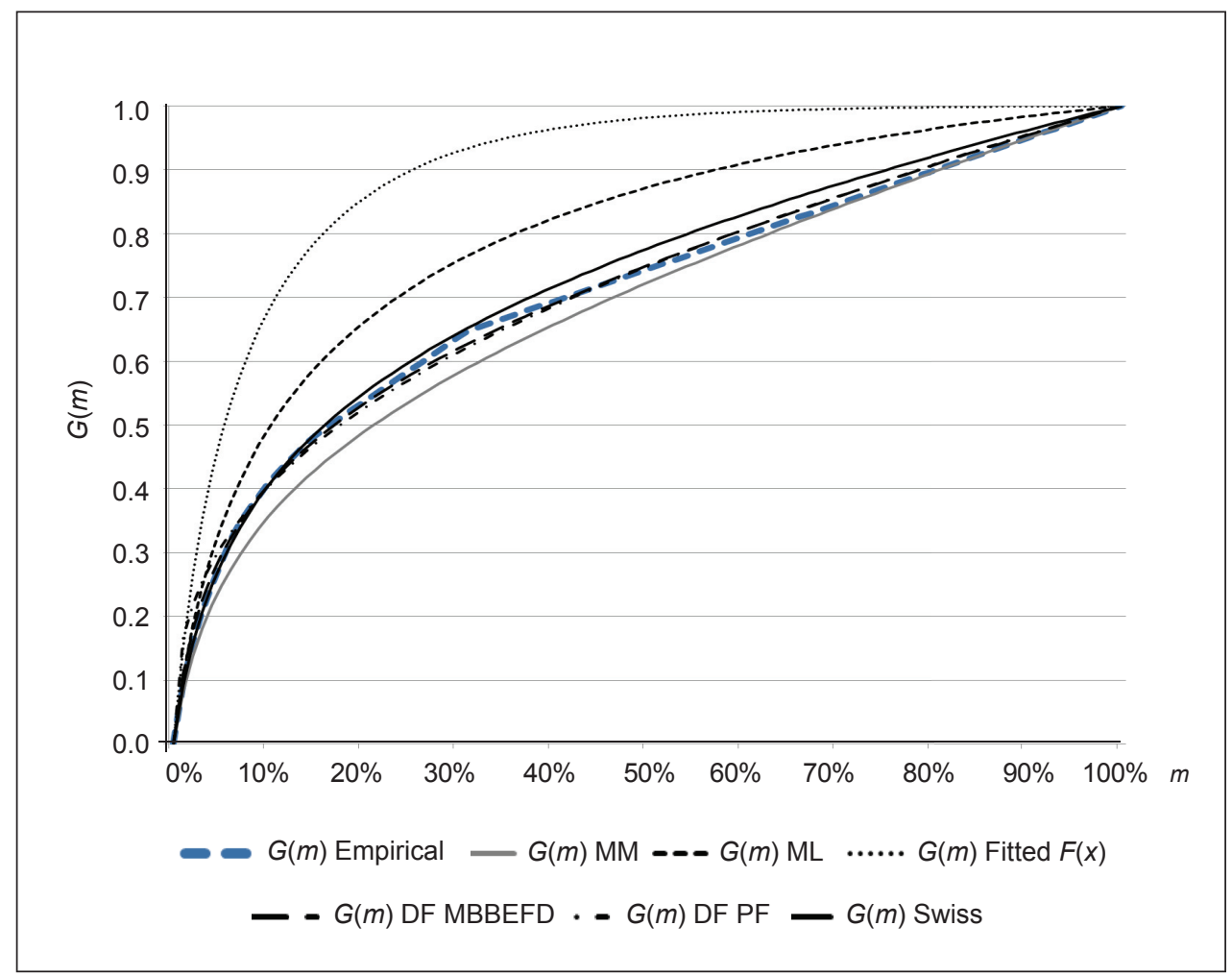

Source: Own calculations

8 For parameterisation of the curves by the non-linear regression it would be better to use appropriate techniques, like calculating the first estimations of parameters by Marquardt or Steepest Descendent methods which are not so sensitive on the choice of initial parameters. These results can be further used as input estimations for Gauss-Newton method which provides more accurate estimations. The selected approach using MS Excel provides enough accuracy for this work as it is not the aim to focus on non-linear regression techniques. Many details about non-linear regression can be found e.g. in Härdle (1995). 
Table 6 | Comparison of Various Approaches to Fitting the Exposure Curves

\begin{tabular}{|l|c|c|c|c|c|c|c|}
\hline & Empirical & MM & ML & Fitted $\boldsymbol{F}(\boldsymbol{x})$ & DF MBBEFD & DF PL & Swiss 3 \\
\hline $\boldsymbol{G}^{\prime}(\mathbf{0})$ & 10.219 & 10.219 & 12.744 & 18.041 & 15.685 & n.a. & 11.471 \\
\hline $\boldsymbol{G}^{\prime}(\mathbf{1})$ & 0.511 & 0.511 & 0.151 & 0.005 & 0.456 & n.a. & 0.375 \\
\hline$\hat{\boldsymbol{p}}$ & 0.050 & 0.050 & 0.012 & 0.000 & 0.029 & n.a. & 0.033 \\
\hline$\hat{\boldsymbol{E}}(\boldsymbol{x})$ & 0.098 & 0.098 & 0.078 & 0.055 & 0.064 & n.a. & 0.087 \\
\hline$\hat{\boldsymbol{b}}$ & n.a. & 15.963 & 0.284 & 0.002 & 13.394 & n.a. & 3.669 \\
\hline$\hat{\boldsymbol{g}}$ & 20.000 & 20.000 & 84.630 & $3,724.619$ & 34.375 & n.a. & 30.569 \\
\hline $\mathbf{R S S}$ & n.a. & 0.101 & 0.983 & 4.677 & 0.008 & 0.025 & n.a. \\
\hline
\end{tabular}

Source: Own calculations

As a common practise method for measuring the fit empirical and theoretical distribution the residual sum of squares criterion is applied

$$
R S S=\sum_{i=1}^{n}\left(G_{\text {Empirical }}\left(m_{i}\right)-G_{\text {Fitted }}\left(m_{i}\right)\right)^{2} .
$$

All the three methods MM, DF PF and DF MBBEFD provided very good results.

As the probabilistic loss distribution in analytical form cannot be derived from the DF PL method, the method of moments would be the recommended option to get initial estimates of unknown parameters and further DF MBBEFD method would be applied.

The parameters obtained from MM were also used as initial parameters for the method of maximum likelihood. The method based on fitting the distribution function $F(x)$ was the least accurate. For comparison, also Swiss 3 curve is included in Figure 4 as initially the observations were generated from its probabilistic distribution.

\subsection{Swiss Re exposure curves as special case}

Already before Bernegger (1997) published his paper the so called Swiss Re exposure curves existed and were widely used. He also parameterized these curves with help of MBBEFD distributions and after evaluating the estimations of parameters $b, g$ he formulated the dependency between the total loss probability $p=1 / g$ and expected degree of damage $E(x)$. In the next step he defined a new sub-class of the one-parameter MBBEFD exposure curves as:

$$
G_{c}(m)=G_{b_{c}, g_{c}}(m)
$$

$9 \quad$ Method called DF PL is based on different parameterisation of exposure curve according to the function described by formula (29), therefore only RSS is displayed. Based on this parameterisation the estimated values of parameters are $\hat{\beta}_{1}=-0.060$ and $\hat{\beta}_{2}=0.388$. 
with

$$
\begin{aligned}
& b_{c}=b(c)=e^{3.1-0.15(1+c) c} \\
& g_{c}=g(c)=e^{(0.78+0.12 c) c} .
\end{aligned}
$$

For $c=0$ the curve corresponds to the total loss distribution (diagonal on Figure 1), the curves defined by $\mathrm{c}=\{1.5 ; 2.0 ; 3.0 ; 4.0\}$ correspond to Swiss Re curves and $c=5$ corresponds to Lloyd's curve used for heavy industrial business. The Table 7 shows the overview of Swiss Re curves and recommendation for their use.

\begin{tabular}{|c|c|c|c|c|c|c|c|c|c|}
\hline $\begin{array}{l}\text { Exp. } \\
\text { Curve }\end{array}$ & c & b & g & $\begin{array}{c}P \\
(\%)\end{array}$ & $\begin{array}{l}E(x) \\
(\%)\end{array}$ & Scope of application & Basis & $\begin{array}{l}\text { Size of Risk } \\
\text { (CHF, 2004) }\end{array}$ & $\begin{array}{l}\text { Size of Risk } \\
\text { (EUR, 2013) }\end{array}$ \\
\hline & n.a. & n.a. & n.a. & n.a. & n.a. & $\begin{array}{l}\text { OPC business } \\
\text { interruption }\end{array}$ & MPL & - & - \\
\hline \multirow[t]{3}{*}{ Swiss 1} & 1.5 & 12.648 & 4.221 & 23.69 & 34.855 & Personal lines & SI & $<400,000$ & 340,000 \\
\hline & n.a. & n.a. & n.a. & n.a. & n.a. & $\begin{array}{l}\text { OPC property damage/ } \\
\text { business interruption }\end{array}$ & MPL & - & - \\
\hline & n.a. & n.a. & n.a. & n.a. & n.a. & OPC property damage & MPL & - & - \\
\hline Swiss 2 & 2.0 & 9.025 & 7.691 & 13.00 & 22.609 & $\begin{array}{l}\text { Commercial lines } \\
\text { (small-scale) }\end{array}$ & SI & $<1,000,000$ & 850,000 \\
\hline \multirow[t]{4}{*}{ Swiss 3} & 3.0 & 3.669 & 30.569 & 3.27 & 8.718 & $\begin{array}{l}\text { Commercial lines } \\
\text { (medium-scale) }\end{array}$ & SI & $<2,000,000$ & $1,700,000$ \\
\hline & 3.1 & 3.299 & 35.559 & 2.81 & 7.891 & $\begin{array}{l}\text { Captive business } \\
\text { interruption }\end{array}$ & MPL & - & - \\
\hline & 3.4 & 2.354 & 56.781 & 1.76 & 5.836 & $\begin{array}{l}\text { Captive property } \\
\text { damage/business } \\
\text { interruption }\end{array}$ & MPL & - & - \\
\hline & 3.8 & 1.439 & 109.596 & 0.91 & 3.895 & $\begin{array}{l}\text { Captive property } \\
\text { damage }\end{array}$ & MPL & - & - \\
\hline Swiss 4 & 4.0 & 1.105 & 154.470 & 0.65 & 3.185 & $\begin{array}{l}\text { Industrial and large } \\
\text { commercial? }\end{array}$ & MPL & $>2,000,000$ & $1,700,000$ \\
\hline \multirow[t]{2}{*}{ Lloyd's } & 5.0 & 0.247 & 992.275 & 0.10 & 1.215 & Industry & $\begin{array}{l}\text { Top } \\
\text { location }\end{array}$ & - & - \\
\hline & $\begin{array}{l}\text { up } \\
\text { to } 8\end{array}$ & n.a. & n.a. & n.a. & n.a. & $\begin{array}{l}\text { Large-scale industry/ } \\
\text { multinational } \\
\text { companies }\end{array}$ & MPL & - & - \\
\hline
\end{tabular}

Table 7 | Overview of Swiss Re Exposure Curves and their Parameters under MBBEFD

Source: Own calculations, Guggisberg (2004), Swiss Federal Statistical Office (2013)

The original Swiss Re curves, also called Gasser curves, were developed by Peter Gasser based on the data of "Fire statistics of the Swiss Association of Cantonal Fire Insurance Institutions" for the years 1959-1967 and due to the fact that they are based on relative degree of damage (i.e. do not develop by inflation over years as it can be easily assumed the same inflation for both values of risks and corresponding claim amounts applies). The "Scope of application" column in Table 7 serves as an indication which exposure curve should be used for which band from risk profile. Also the size of risk gives 
a good indication as in many cases the risk profiles are not separated by personal lines, commercial lines, etc. The original size of risk indicator suggested by Guggisberg (2004) was given in Swiss Francs (CHF) and in 2004 values (prices), therefore an alternative in EUR and 2013 values was calculated and rounded generously (tens of thousands EUR). For this recalculation Swiss consumer prices index and rate of exchange 0.81 EUR / 1 CHF were used.

What is also important to mention is that various CDFs of degrees of damage do not smoothly converge to the cumulative probability at the point 1 at their maximums (examples are shown for Swiss Re curves on Figure 5) and this is why there is a different form of function $F(x)$ for $x<1$ and for $x=1$ in formula (21), the CDF is not continuous function.

Figure 5 | CDFs Comparison of Degree of Damage for Swiss Re Curves

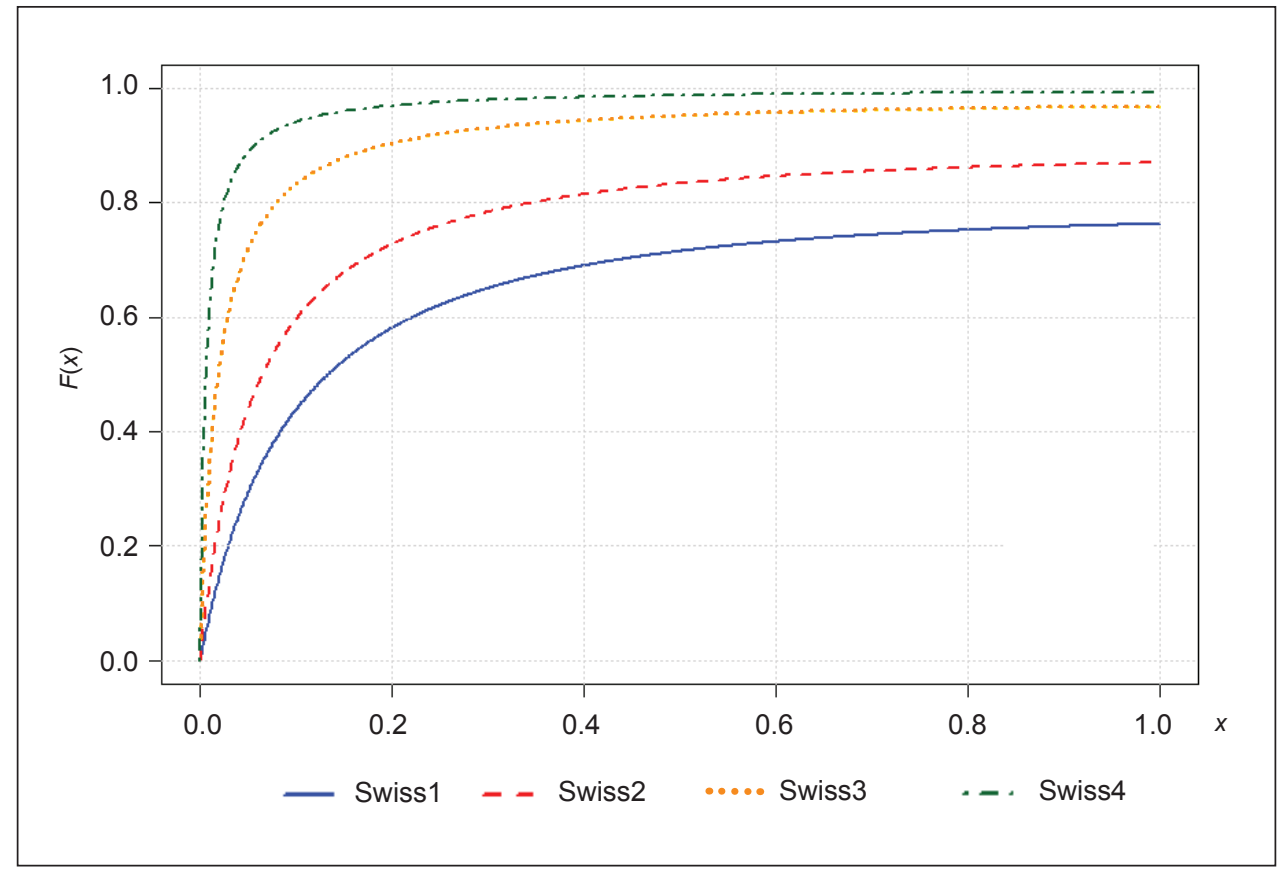

Note: $F(x)$ for $x<1$.

Source: Own calculations, Guggisberg (2004), Bernegger (1997)

It can be further shown that for general cases of parameters $b, g$ and for $\mathbf{x} \in(\infty)$ (i.e. without further restrictions ${ }^{10}$ for $\mathbf{x}$ as introduced in formula (21)) and where $\mathbf{x}$ is MBBEFD distributed, the distribution function $F(x)$, would not have maximum and the CDF would converge to

10 By definition of exposure curves for CDF of degree of damage $F(x=1)=1$ applies (formula (20)), therefore sharp step (discontinuity) in the tail of $F(x)$ can be observed. 


$$
\lim _{x \rightarrow \infty} F(x)=1-\frac{1-b}{1-g b} .
$$

It is also interesting to show some dependencies of selected characteristics on the parameter $c$, brief comparison is shown in Table 8. For each exposure curve 1,000,000 simulations of degree of damage were ran and various statistics on their basis calculated. When comparing mean degree of damage for each curve from simulated sample in Table 8 and for theoretical values in Table 7 the results are very close and 1 Mio. simulations seem to be enough. Also $\operatorname{Var}(\mathrm{x})$ is decreasing with increasing $c$ parameter.

All distributions of Swiss Re curves are positively (right) skewed and the higher the $c$ parameter the more the right tail of the distribution is stretched from the centre. The moment method for calculating the skewness was used as it is more suitable for resampling ${ }^{11}$. Kurtosis measures how "peaked" the probabilistic distribution is and again moment method of calculation was used and the higher the $c$ parameter the higher kurtosis can be expected.

Table 8 | Comparison of MBBEFD Distributions Characteristics of x for Swiss Re Curves Parameters

\begin{tabular}{|l|c|c|c|c|}
\hline & Swiss1 & Swiss2 & Swiss3 & Swiss4 \\
\hline$\hat{\boldsymbol{E}}(\boldsymbol{x})$ & 0.34842 & 0.22580 & 0.08741 & 0.03161 \\
\hline $\boldsymbol{V a ̂}(\boldsymbol{x})$ & 0.15654 & 0.11119 & 0.04056 & 0.01110 \\
\hline Skewness & 0.86352 & 1.63042 & 3.63288 & 7.02407 \\
\hline Kurtosis & 1.98132 & 4.06347 & 15.81750 & 58.48595 \\
\hline
\end{tabular}

Source: Own calculations, Bernegger (1997)

\section{Deriving Loss Severity Distribution and Frequency from MBBEFD Exposure Curves}

Once it is decided which exposure curve should be used for reinsurance modelling and its parameters $b, g$ are known, for any further stochastic modelling number of losses ${ }_{\text {loss }} \mathbf{N}$ and the respective individual loss amounts $\mathbf{X}$ need to be simulated.

The following theory is based on selected $h$-th risk profile band, however, it can be also used for any $i$-th single risk, where in the following formulas $V_{i}$ and $R P_{i}$ would be used instead of $\bar{V}^{h}$ and $\hat{E}\left(\mathbf{Z}^{h}\right)$ respectively.

From the collective risk model and from (16) the expected number of gross losses can be expressed as

$$
\begin{aligned}
E\left({ }_{\text {loss }} \mathbf{N}^{h}\right) & =E\left(\mathbf{Z}^{h}\right) / E\left(\mathbf{X}^{h}\right)= \\
& =\frac{E\left(\mathbf{Z}^{h}\right)}{\bar{V}^{h} E\left(\mathbf{x}^{h}\right)}=\frac{E\left(\mathbf{Z}^{h}\right)}{\bar{V}^{h}} G^{\prime}(0)
\end{aligned}
$$

and more general for losses exceeding given threshold $U$ as

11 R software also offers Fisher method which is based on unbiased sample variance. 


$$
\begin{aligned}
E\left({ }_{\operatorname{loss}} \mathbf{N}^{h} \mid \mathbf{x}>\frac{U}{\bar{V}^{h}}\right) & =E\left({ }_{\text {loss }} \mathbf{N}^{h} \mid \frac{\mathbf{X}^{h}}{\bar{V}^{h}}>\frac{U}{\bar{V}^{h}}\right)= \\
& =\frac{E\left(\mathbf{Z}^{h}\right)}{\bar{V}^{h}} G^{\prime}\left(\frac{U}{\bar{V}^{h}}\right),
\end{aligned}
$$

where the derivative of exposure curve as function of normalised retention $m$ is defined in Bernegger (1997) as

$$
G^{\prime}(m)= \begin{cases}1 & g=1 \vee b=0 \\ \frac{g-1}{\ln (g)(1+(g-1) m)} & b=1 \wedge g>1 \\ \frac{\ln (b) b^{m}}{b-1} & b g=1 \wedge g>1 \\ \frac{\ln (b)(1-g b)}{\ln (g b)\left((g-1) b^{1-m}+(1-g b)\right)} & b>0 \wedge b \neq 1 \wedge b g \neq 1 \wedge g>1 .\end{cases}
$$

Further, for each threshold $U$ the mean excess function can be calculated as

$$
E\left(\mathbf{X}^{h}-U \mid \mathbf{X}^{h}>U\right)=\frac{E\left(\mathbf{Z}^{h}\right)\left(1-G\left(\frac{U}{\bar{V}^{h}}\right)\right)}{E\left({ }_{\text {loss }} \mathbf{N}^{h} \mid \mathbf{X}^{h}>U\right)}
$$

and the conditional mean individual loss can be expressed as

$$
E\left(\mathbf{X}^{h} \mid \mathbf{X}^{h}>U\right)=\frac{E\left(\mathbf{Z}^{h}\right)\left(1-G\left(\frac{U}{\bar{V}^{h}}\right)\right)}{E\left(\text { loss }^{h} \mid \mathbf{X}^{h}>U\right)}+U=E\left(\mathbf{X}^{h}-U \mid \mathbf{X}^{h}>U\right)+U .
$$

Once the expected number of losses for each threshold is computed, the CDF for size of the individual loss $F(X)$ can be calculated iteratively. As it is not always suitable to derive the $\mathrm{CDF}$ for all losses Sometimes only large losses are of interest. Let's denote ${ }_{0} U$ as basis threshold and elements of the vector $\mathbf{U}=\left\{{ }_{0} U,{ }_{1} U, \ldots,{ }_{D-1} U\right\}$ will define the elements of vector $\mathbf{X}=\left\{{ }_{0} X,{ }_{1} X, \ldots,{ }_{D-1} X\right\}$ for which respective percentiles should be calculated in $D-1$ iterations. The conditional CDF of size of the loss in $d$-th iteration can be then expressed as

$$
F\left({ }_{d} X^{h}={ }_{d} U \mid \mathbf{X}^{h}>{ }_{0} U\right)=1-\frac{E\left({ }_{\text {loss }} \mathbf{N}^{h} \mid \mathbf{X}^{h}>{ }_{d} U\right)}{E\left({ }_{\text {loss }} \mathbf{N}^{h} \mid \mathbf{X}^{h}>{ }_{0} U\right)},
$$

where $\mathrm{d} \in\{0,1, \ldots, D-1\}$. 
An alternative option of computing the number of expected claims above threshold exists. This method is also iterative and in each iteration it is based on creation of artificial layer with limit of one unit (e.g. 1 EUR, $1 \mathrm{CZK}$ etc.) in excess of each ${ }_{d} U$, i.e. in each $d$-th iteration an artificial layer with limit $L=1$ ad retention $M={ }_{d} U$ is created. By applying the exposure curve parameters $G(\mathrm{~m})$ and calculating the ceded loss into each of the artificial layers according to formula (10) the expected number of claims above threshold is obtained as from each claim 1 EUR or CZK is ceded. More formally the expected number of claims above threshold can be written as

$$
E\left(\mathbf{Z}_{r e, 1 \times s_{d} U}^{h}\right)=E\left({ }_{\text {loss }} \mathbf{N}^{h} \mid \mathbf{X}^{h}>_{d} U\right),
$$

where $E\left(\mathbf{Z}_{r e, 1 \times x_{d} U}^{h}\right)$ denotes mean ceded loss to layer with limit of $L=1$ and $M={ }_{d} U$. The calculation of $F(X)$ is then identical to the previous method, i.e. according to the formula (39).

Once distributions of degree of damage and frequency are parameterised (for frequency Poisson distribution will be assumed) the gross losses for each band can be simulated. For simulating the losses from severity model the inverse transform method (also known as probability integral transform method) can be applied. Assuming the degree of damage distribution parameters are known and for each $i$-th loss $\mathbf{x} \sim \operatorname{MBBEFD}(b, g)$ (i.e. all losses have identical distribution of degree of damage) and $\mathbf{r} \sim$ uniform, than

$$
\mathbf{x}=F^{-1}(\mathbf{r}) .
$$

Further, as size of any $i$-th loss $\mathbf{X}_{i}=\mathbf{x}_{i} \cdot V_{i}$, where value of risk $V_{i}$ is deterministic and further assuming that for all risks from $h$-th band $V_{i}^{h}=\bar{V}^{h}$ then the random loss for $h$-th band can be expressed as

$$
\mathbf{X}=F^{-1}(\mathbf{r}) \cdot \bar{V}^{h}
$$

From (21), (33) and (32) the gross individual loss for $h$-th band is then defined as

$$
\mathbf{X}= \begin{cases}\bar{V}^{h} \cdot\left(1-\log _{b}\left(\frac{\frac{1-b}{1-\mathbf{r}}-1+g * b}{g-1}\right)\right) & \mathbf{r}<1-\frac{1-b}{1-g b} \\ \bar{V}^{h} & \mathbf{r} \geq 1-\frac{1-b}{1-g b} .\end{cases}
$$

\section{Case Study}

For the more complex and more realistic illustration of property exposure rating the risk profile from Table 1 was analysed and for various bands various Swiss Re curves were chosen as shown in Table 9 below. 
Table 9 | Selected Swiss Re Curves by Risk Profile Bands

\begin{tabular}{|l|r|r|c|}
\hline $\boldsymbol{h}$ & \multicolumn{2}{|c|}{ Bands of $\boldsymbol{V}$} & Exposure Curve \\
\hline $\mathbf{1}$ & 0 & 500,000 & Swiss 1 \\
\hline $\mathbf{2}$ & 500,001 & $1,000,000$ & Swiss 2 \\
\hline $\mathbf{3}$ & $1,000,001$ & $1,500,000$ & Swiss 3 \\
\hline $\mathbf{4 - 1 2}$ & $1,500,001$ & $7,000,000$ & Swiss 4 \\
\hline
\end{tabular}

Source: Own calculations

Further, for each of the bands of the risk profile the expected annual numbers of losses were estimated and their amounts used as Poisson distribution parameters $\hat{\lambda}^{h}$ for each $h$-th band. The estimated $\hat{\lambda}^{h}$ were calculated from formula (34) and their values are shown in Table 10.

Table 10 | Expected Number of Losses per Band

\begin{tabular}{|l|c|c|c|c|}
\hline $\boldsymbol{h}$ & \multicolumn{2}{|c|}{ Bands of $\boldsymbol{V}$} & $\boldsymbol{G}^{\prime}\left(\overline{\boldsymbol{m}}^{h}\right)$ & $\hat{\boldsymbol{\lambda}}^{h}$ \\
\hline $\mathbf{1}$ & 0 & 500,000 & 2.8690 & 861.8756 \\
\hline $\mathbf{2}$ & 500,001 & $1,000,000$ & 4.4230 & 81.6270 \\
\hline $\mathbf{3}$ & $1,000,001$ & $1,500,000$ & 11.4706 & 47.1257 \\
\hline $\mathbf{4}$ & $1,500,001$ & $2,000,000$ & 31.3952 & 53.5415 \\
\hline $\mathbf{5}$ & $2,000,001$ & $2,500,000$ & 31.3952 & 23.9506 \\
\hline $\mathbf{6}$ & $2,500,001$ & $3,000,000$ & 31.3952 & 21.1418 \\
\hline $\mathbf{7}$ & $3,000,001$ & $3,500,000$ & 31.3952 & 11.9219 \\
\hline $\mathbf{8}$ & $3,500,001$ & $4,000,000$ & 31.3952 & 7.5615 \\
\hline $\mathbf{9}$ & $4,000,001$ & $4,500,000$ & 31.3952 & 6.7755 \\
\hline $\mathbf{1 0}$ & $4,500,001$ & $5,000,000$ & 31.3952 & 3.2449 \\
\hline $\mathbf{1 1}$ & $5,000,001$ & $6,000,000$ & 31.3952 & 6.2488 \\
\hline $\mathbf{1 2}$ & $6,000,001$ & $7,000,000$ & 31.3952 & 5.1483 \\
\hline
\end{tabular}

Source: Own calculations

Further, for each $h$-th band 100,000 years were simulated, the claims were simulated with threshold of ${ }_{0} U=0$, i.e. the simulations generated both attritional and large losses. The reinsurance structure applied was the same as in the previously demonstrated example 
in Table 3, i.e. limit $L=6 \mathrm{Mio}$, retention $M=1 \mathrm{Mio}$. and unlimited number of free reinstatements were applied. The main aim of non-proportional excess of loss reinsurance is to protect a cedant against large single claims and decrease the volatility of retained losses, the results based on Monte Carlo simulations are shown in Table 11. Based on simulations the total estimated mean losses retained by cedant were slightly reduced by reinsurance, this is due to the obvious fact valid in insurance business that the majority of claims come from attritional losses, whilst only large losses are meant to be subject of excess of loss reinsurance. It can be also seen in Table 1 that only losses from limited number $(2.6 \%)$ of risks in the portfolio can theoretically trigger the retention. The volatility measured by sample standard deviation is again reduced due to the reinsurance (from 6.5 Mio. for gross loss to 5.4 Mio. for net loss). Table 11 also demonstrates, how volatile such structure for reinsurer is, coefficient of variation of ceded losses amounts to $79.86 \%$ which is relatively high, however, not unusual level in such type of reinsurance.

Table 11 | Selected Results of Exposure Rating for Total Loss

\begin{tabular}{|l|c|c|c|}
\hline & Gross & Ceded & Net \\
\hline Numbers of simulations & 100,000 & 100,000 & 100,000 \\
\hline Mean & $106,330,654$ & $3,080,670$ & $5,439,386$ \\
\hline Standard deviation & $6,469,931$ & $2,460,130$ & $5.27 \%$ \\
\hline Coefficient of variation & $6.08 \%$ & $79.86 \%$ & $82,339,861$ \\
\hline Minimum & $82,339,861$ & & $128,784,502$ \\
\hline Maximum & $137,487,504$ & $21,195,537$ & $110,301,821$ \\
\hline VaR 0.9 & $114,784,490$ & $6,500,002$ & $116,237,140$ \\
\hline VaR 0.99 & $122,441,240$ & $10,877,098$ & $117,634,710$ \\
\hline VaR 0.995 & $124,324,079$ & $12,054,375$ & $118,077,675$ \\
\hline VaR 0.996 & $124,900,576$ & $12,381,433$ & 103 \\
\hline
\end{tabular}

Note: Estimations based on Monte Carlo simulations.

Source: Own calculations

Some of the estimated percentiles which are used in practice were further added into Table 11 (denoted as VaR from "Value at Risk"). The 99.5-th percentile is often used for Solvency II purposes, whilst the 99.6-th percentile has been traditionally used by reinsurance buyers. When such rule should be applied in deciding about the number of reinstatements the cedant needs, the 99.6-th percentile of ceded loss is slightly above 12 Mio. which would lead to recommendation to buy one or maximum two reinstatements (from 99.5-th percentile of ceded loss in Table 11 the $1^{\text {st }}$ reinstatement would be fully exhausted only with $0.5 \%$ probability, which very low). For illustration the cumulative 
distribution functions based on Monte Carlo simulations are shown on Figure 6, the limited effect of such type of reinsurance on mean retained loss is clearly visible.

Figure 6 | CDFs Comparison of Gross, Ceded and Net Loss

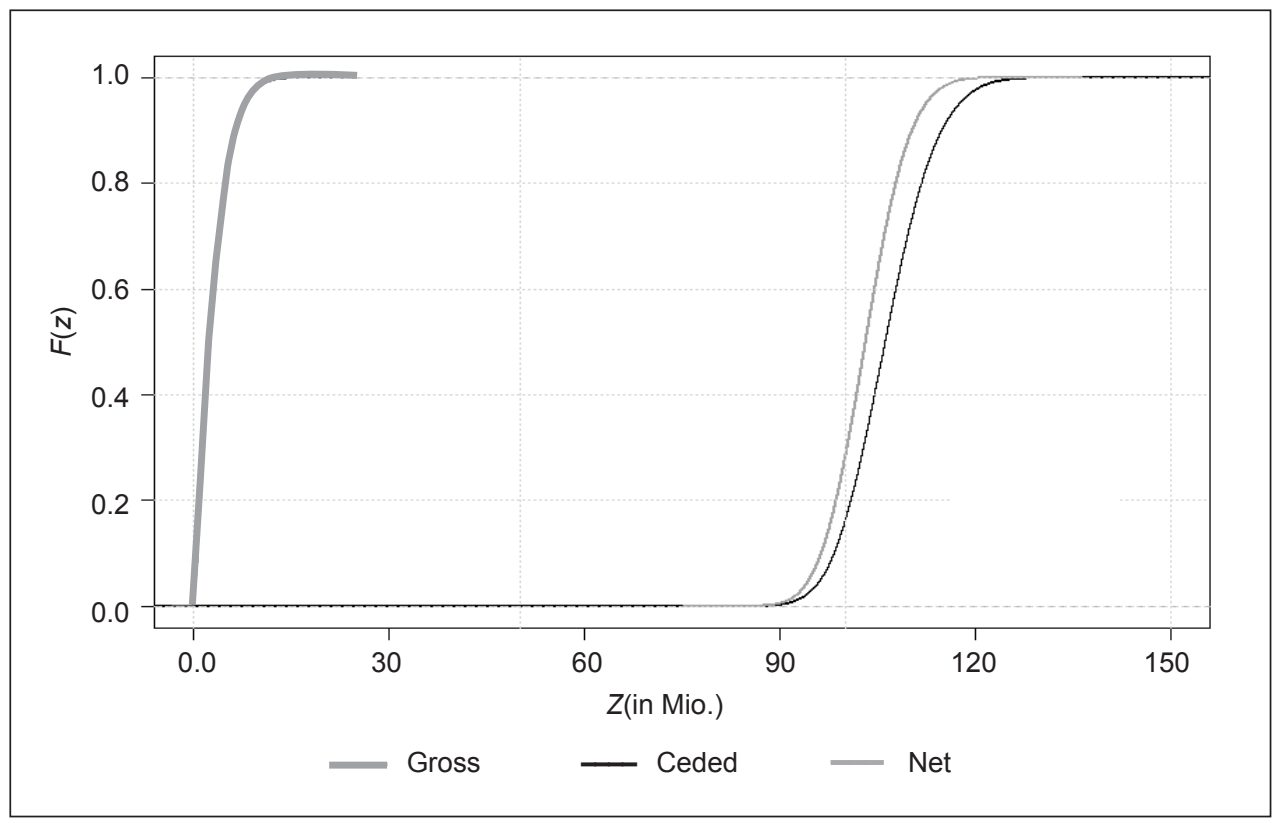

Source: Own calculations

\section{Conclusion}

Exposure rating is a powerful alternative to traditional modelling approaches based on historical claims data and when such historical data of the cedant is not available it is the only possible modelling approach which can be used. Such exposure based approach is also very useful for situations when a reinsurance buyer changed its underwriting approach and historical claims are not any longer representative for future projections.

Unfortunately, only limited number of papers on the topic of exposure rating exist and each of the papers deals with slightly different issue. This paper provides comprehensive description of the methodology and can serve as a guide how to construct exposure curves and how to apply the methodology for the purpose of reinsurance modelling. All the methods are further demonstrated on numerical examples.

One of the weaknesses of the property exposure rating methodology is a very high degree of subjectivity when choosing an appropriate exposure curve. The choice of the curve always requires an in-depth knowledge of the analysed portfolio. Further, the curves are often based on very old data, although they are resistant to inflation, the insurance covers (products) have changed historically. 
Very often a combined risk profile is provided which includes all homeowners, commercial and also large industrial risks, in such situation it is very important to decide by value of risks which curve should be used for which band. Sometimes it is also helpful to blend the exposure curves and apply the combined curve on some band of risk profile which includes combination of various types of risks. Further, for various bands might be applied various estimated loss ratios, unfortunately, not enough information is usually provided by the cedant to make such assumptions.

\section{References}

Bernegger, S. (1997). The Swiss Re Exposure Curves and MBBEFD Distribution Class. ASTIN Bulletin, 27(1), 99-111, https://doi.org/10.2143/ast.27.1.563208

Daykin, C. D., Pentikäinen, T., Pesonen, M. (1995). Practical Risk Theory for Actuaries. Suffolk: Chapman \& Hall, ISBN 978-0412428500.

Guggisberg, D. (2004). Exposure Rating. Zurich: Swiss Re.

Härdle, W. (1995). Applied Nonparametric Regression. Cambridge: Cambridge University Press.

Ludwig, S. (1991). An Exposure Rating Approach to pricing Property Excess-of-Loss Reinsurance. PCAS, 78, 110-145, https://www.casact.org/pubs/proceed/proceed91/91110.pdf

Salzmann, E. R. (1963). Rating by Layer of Insurance. Proceedings of the Casualty Actuarial Society, 50, 15-26, https://www.casact.org/pubs/proceed/proceed63/1963.pdf

White, S. (2005). Property Ratemaking - An Advanced Approach, Exposure Rating. Lecture at Seminar on Reinsurance, Hamilton. 